\title{
Chronic Kidney Disease: Clinical and Epidemiological Scenario of Patients in Hemodialysis
}

\author{
Liliane Bernardes Campos ${ }^{1}$, Mônica Cristina Toffoli-Kadri ${ }^{1,2}$ \& Vanessa Terezinha Gubert ${ }^{1,2,3}$ \\ ${ }^{1}$ Postgraduate Program in Pharmaceutical Sciences, Faculty of Pharmaceutical Sciences, Food, and Nutrition, \\ Federal University of Mato Grosso do Sul, Campo Grande, Mato Grosso do Sul, Brazil \\ ${ }^{2}$ Faculty of Pharmaceutical Sciences, Food, and Nutrition, Federal University of Mato Grosso do Sul, Campo \\ Grande, Mato Grosso do Sul, Brazil \\ ${ }^{3}$ Pharmacy School Prof ${ }^{a}$ Ana Maria Cervantes Baraza, Faculty of Pharmaceutical Sciences, Food, and Nutrition, \\ Federal University of Mato Grosso do Sul, Campo Grande, Mato Grosso do Sul, Brazil
}

Correspondence: Vanessa Terezinha Gubert, Pharmacy School Prof ${ }^{a}$ Ana Maria Cervantes Baraza, Faculty of Pharmaceutical Sciences, Food, and Nutrition, Federal University of Mato Grosso do Sul, Campo Grande, Mato Grosso do Sul, Brazil. Tel: 55-67 3345-7781.

Received: October 9, 2020 Accepted: January 25, 2021 Online Published: May 31, 2021

doi:10.5539/gjhs.v13n7p61 URL: https://doi.org/10.5539/gjhs.v13n7p61

\begin{abstract}
Objective: To describe the clinical and epidemiological scenario of patients with chronic kidney disease undergoing hemodialysis.

Method: Retrospective study with secondary data collected from the medical records of patients over 18 years of age on hemodialysis from January 2016 to December 2018.

Results: 507 patients underwent ambulatory and/or hospital hemodialysis during the study period. From these, 494 participants were included, comprising 383 who were still under treatment at the end of the study period and 111 who died during the study period. The majority of hemodialysis patients were male, with a mean age of 56.6 years, non-white (77.4\%), in a stable relationship (51.6\%), retired (54.9\%), and with low education (73.9\%). Most participants started hemodialysis with the use of a central venous catheter $(83.3 \%)$, which was maintained for $43.8 \%$ of the treatment time. Participants used an average of 18.91 medications daily. More than half of the deaths occurred during the first two years of treatment, with $30.6 \%$ of these occurring in the first 12 months of hemodialysis. Evaluation of the results of the clinical outcome of death demonstrated a relationship between age $(p=0.003)$, number of comorbidities $(p=0.009)$, time using a central venous catheter $(p=0.025)$, and white ethnicity $(\mathrm{p}=0.021)$. Septic shock was the main cause of death $(56.8 \%)$.

Conclusion: Some factors related to the prognosis of the disease cannot be changed, such as age and white ethnicity. However, greater attention to the management and adequate monitoring of comorbidities is necessary, as well as a reduction in the time spent using a central venous catheter. Due to polymedication, pharmacotherapeutic monitoring is indicated, both for the prevention of drug related problems and for discussions concerning drug discontinuation.
\end{abstract}

Keywords: chronic renal failure, epidemiology, mortality, renal dialysis

\section{Introduction}

The incidence rate of chronic kidney disease (CKD) continues to increase progressively each year. In 2016, Taiwan, the United States, and the Jalisco region of Mexico had the highest incidences of patients undergoing treatment for chronic renal failure (CRF), with rates of 493, 378, and 355 patients per million (ppm) of the general population, respectively (United States Renal Data System, 2018). According to data from the Brazilian chronic dialysis survey 2017, Brazil had an average annual increase in the number of dialysis patients of approximately $6 \%$. It is estimated that, in 2017, approximately 127,000 people were on an outpatient dialysis program and the incidence rate has reached $194 \mathrm{ppm}$. In Mato Grosso do Sul, the prevalence rate was estimated at $678 \mathrm{ppm}$ in 2016, totaling 1,818 patients undergoing chronic dialysis (Sesso, Lopes, Thomé, Lugon, \& Martins, 2017).

Certain comorbidities are frequent among dialysis patients, such as systemic arterial hypertension (SAH), diabetes 
mellitus (DM), cardiovascular disease, metabolic disorders, and obesity (Stenvinkel, Zoccali, \& Ikzler, 2013; Albertus, Morgenstern, Robinson, \& Saran, 2016; Johnson et al., 2016). Complications acquired from or related to a decline in renal function include uremia, anemia, hyperkalemia, hyperparathyroidism, hyperphosphatemia and hyperkalemia. Additionally, dialysis patients are often exposed to nosocomial infections secondary to necessary treatment procedures (Hill et al., 2016; Bello et al., 2017; Hanudel, Froch, Wales, Jüppner, \& Salusky, 2017; Swaminathan, Mor, Mehrotra, \& Trivedi, 2017; Vilay, 2019).

Dialysis patients are affected by required changes in lifestyle, including restrictive diets, controlled fluid intake, and frequent, lengthy visits to dialysis facilities in addition to the potential side effects of the therapy, which include pain, nausea, emesis, cramps, and malaise (Ribeiro, Alencar, Feitosa, \& Mesquita, 2013; Nayana et al., 2017; Fleishman, Dreiher, \& Shvartzman, 2018; Jacobson et al., 2019). Due to these changes imposed by dialysis treatment, as well as its consequences, many patients feel frustrated that they no longer live an active and productive life. Consequently, there is a high rate of depression in this patient population (Nayana et al., 2017; Shirazian, 2019).

Mortality rates in patients with CRF are worrisome, especially at the initiation of treatment (Foley, Chen, Solid, Gilbertson, \& Collins, 2014; Robinson et al., 2014; Wick et al., 2017). Approximately 50\% of dialysis patients have a five-year survival, and the life expectancy of dialysis patients is one third that of the general population when controlling for age and sex (Saran et al., 2017; European Renal Association - European Dialysis and Transplant Association [ERA-EDTA], 2019). In Brazil, annual expenditures on renal replacement therapy (RRT) represent $5 \%$ of the total budget of the Unified Health System (SUS) for medium and high complexity assistance, corresponding to more than 2 billion reais (Alcalde \& Kirsztajn, 2018). In the United States, a country with a high rate of dialysis patients, the annual spending on dialysis treatments amounts to approximately $\$ 38$ billion (USRDS 2018).

Worldwide, CKD mortality has increased $134.6 \%$ over approximately 25 years. Among the main causes of death in hemodialysis (HD) patients are cardiovascular disease, infections, neoplasms, and hyperkalaemia (Naghavi et al., 2015; Pippias et al., 2016). In Brazil, in 2017, mortality in the dialysis population was estimated at 19.9\%, representing more than 25,000 deaths (Thomé, Sesso, Lopes, Lugon, \& Martins, 2019). It is worth mentioning that lack of treatment due to patient refusal or lack of access to a type of RRT leads to the death of more than 2 million people annually worldwide (Liyanage et al., 2015). Still, among the factors that influence survival of patients on HD is the type of vascular access, which may be a determinant of a patient's clinical outcome. The use of central venous catheters (CVCs) has been associated with higher risks of infection, which leads to hospitalizations, high mortality rates, and higher hospital costs (Muci, Tartaglione, Rotondi, Carbone, \& Mazzaferro, 2017; Murray et al., 2018).

With regards to drug treatment, it is estimated that HD patients use approximately 13.5 drugs per day, mainly comprising of antihypertensive drugs, phosphate chelators, antibacterials, hypolipidemics, antithrombotics, erythropoietin, iron, vitamin D and its analogues, anti-ulcer agents, psychotropics, analgesics, and antiemetics (Mclntyre, Mcquillan, Bell, \& Battistella, 2017; USRDS, 2019). Still, according to Scott, Gray, Martin, Pillans, and Mitchell (2012), polymedicated patients may have less adherence to treatment and suffer a greater risk of adverse effects, hospitalizations, and death. Many of the drugs mentioned are metabolized and/or eliminated by the kidneys while others are nephrotoxic, thus making the safe use of drugs by chronic kidney patients a complex process. HD patients require special care regarding control of kidney function, and special attention must be paid regarding possible changes in the pharmacokinetics and pharmacodynamics of the drugs used in the face of declining renal function (Matzke et al., 2011).

Knowing the current scenario of HD patients can contribute to the development of actions that reduce the morbidity and mortality rates of this population, the high rates of hospitalization and premature deaths, and the considerable costs of medical assistance required by this population. Thus, the aim of this study was to describe the clinical and epidemiological scenario of patients with CKD undergoing HD.

\section{Method}

A retrospective, cross-sectional study was carried out in a large hospital with two urgency and emergency care units (approximately 5,837 visits per month), 18 inpatient units with 495 public and 117 private beds, nine intensive care units containing 86 beds, and a neonatal intermediate unit containing 11 beds. The hospital's HD service is a reference for users of the Brazilian public health system and serves an average of 44 patients per day.

Patients aged 18 years or older who underwent HD at the institution sometime between January 1, 2016, and December 31, 2018 were included. Medical records of patients with acute renal failure were excluded. 
Secondary data were obtained from the medical records of patients who met the inclusion criteria, with sociodemographic and clinical information being collected. Among the sociodemographic information collected, data on gender, age, ethnicity, marital status, education, profession, origin, and place of birth were collected. Comorbidities, treatment, type of vascular access, adherence to HD sessions, and the date and cause of death were collected as clinical information. The vascular access used at the beginning of treatment was analyzed only for patients who started HD therapy between January 2016 and December 2018. Adherence to HD was considered only for patients undergoing outpatient treatment between January 2016 and December 2018. To assess adherence to HD treatments, the presence of each patient at their scheduled HD sessions was considered and patients with less than three absences per year of treatment were considered adherent.

This work was approved by the Research Ethics Committee involving Human Beings, with the waiver of the Informed Consent Form (ICF) being waived for the medical records of patients who died, transferred, or were not being treated at the institution during the period of data collection. Patients identified as being treated at the service during data collection were invited to participate in the study and were included in the study by signing the ICF.

The collected data were statistically analyzed using the SPSS program (Statistical Package for the Social Sciences) version 23.0. Most associations were performed using the chi-square test, while the associations between adherence and age, adherence and number of comorbidities, death and age, and the amount of comorbidities and type of access used during treatment were performed using the student's t-test. A value of $p<0.05$ was considered statistically significant and the Kaplan-Meier method was used to estimate the survival time.

\section{Results and Discussion}

Between 2016 and 2018, 507 patients underwent ambulatory or hospital HD at the study site. Of these patients, 13 were excluded because they had a diagnosis of acute renal failure. Thus, 494 patients were included in the study, with 383 (77.5\%) being treated and 111 (22.5\%) dying during the study period.

Regarding the age of the participants at the beginning of HD treatment, six participants who started HD under the age of 18 were identified, specifically being $5,12,14,15$, and two participants being 17 years of age. Of the total number of participants who started HD at the age of 60 or over, there were 118 participants aged between 60 and 69 years old, 51 participants aged between 70 and 79 years old, and 13 participants aged between 80 and 89 years old.

Among the 170 participants alive in 2018, 105 were between 60 and 69 years old, 51 were between 70 and 79 years old, 12 were between 80 and 89 years old, and the remainder were aged 91 and 92 years old. Among the 67 participants aged 60 or over who died, 34 were aged between 60 and 69, 26 were between 70 and 79, six were between 80 and 89 , and one patient was aged 90 .

The mean total age of patients at the beginning of HD was $52.38 \pm 0.71$ years (mean \pm standard error of the mean), while patients who died during the study period started $\mathrm{HD}$ at a mean age of $57.21 \pm 1.47$ years, suggesting that the risk of death is greater for those who start HD at an older age. The mean age at death was $60.34 \pm 1.44$ years. Additional sociodemographic characteristics of the chronic renal patients undergoing hospital and outpatient HD are shown in Table 1. 
Table 1. Characterization of patients on hemodialysis $(2016-2018)(n=494)$

\begin{tabular}{|c|c|c|c|}
\hline Variables & $\begin{array}{l}\text { Total } \\
\text { n (\%) }\end{array}$ & $\begin{array}{l}\text { Alive }(n=383) \\
\text { n (\%) }\end{array}$ & $\begin{array}{l}\text { Deaths }(n=111) \\
\text { n }(\%)\end{array}$ \\
\hline \multicolumn{4}{|l|}{ Gender } \\
\hline Male & $278(56.3)$ & $216(56.4)$ & $62(55.9)$ \\
\hline Female & $216(43.7)$ & $167(43.6)$ & $49(44.1)$ \\
\hline \multicolumn{4}{|l|}{ Race } \\
\hline Not white & $382(77.3)$ & $305(79.6)$ & $77(69.4)$ \\
\hline White & $112(22.7)$ & $78(20.4)$ & $34(30.6)$ \\
\hline \multicolumn{4}{|c|}{ Age group at the beginning of hemodialysis } \\
\hline$<18$ years & $6(1.2)$ & $4(1.0)$ & $2(1.8)$ \\
\hline $18-29$ years & $40(8.1)$ & $36(9.4)$ & $4(3.6)$ \\
\hline 30-39 years & $59(12.0)$ & $51(13.3)$ & $8(7.2)$ \\
\hline $40-49$ years & $88(17.8)$ & $70(18.3)$ & $18(16.2)$ \\
\hline $50-59$ years & $117(23.7)$ & $93(24.3)$ & $24(21.6)$ \\
\hline$\geq 60$ years & $184(37.2)$ & $129(33.7)$ & $55(49.6)$ \\
\hline Age group in 2018 & & & * \\
\hline $18-29$ years & $23(4.6)$ & $18(4.7)$ & $5(4.5)$ \\
\hline 30-39 years & $52(10.5)$ & $48(12.5)$ & $4(3.6)$ \\
\hline $40-49$ years & $74(15.0)$ & $59(15.4)$ & $15(13.5)$ \\
\hline $50-59$ years & $108(21.9)$ & $88(23.0)$ & $20(18.0)$ \\
\hline$\geq 60$ years & $237(48.0)$ & $170(44.4)$ & $67(60.4)$ \\
\hline \multicolumn{4}{|l|}{ Marital situation } \\
\hline Stable union & $255(51.6)$ & $206(53.8)$ & $49(44.2)$ \\
\hline Single & $239(48.4)$ & $177(46.2)$ & $62(55.8)$ \\
\hline \multicolumn{4}{|l|}{ Education } \\
\hline Up to 8 years & $280(73.9)$ & $204(74.5)$ & $76(72.4)$ \\
\hline More than 8 years & $99(26.1)$ & $70(25.5)$ & $29(27.6)$ \\
\hline Ignored & $115(23.2)$ & $109(28.5)$ & $6(5.4)$ \\
\hline \multicolumn{4}{|l|}{ Profession } \\
\hline Retired & $271(54.9)$ & $198(51.7)$ & $73(65.8)$ \\
\hline Housewife & $79(16.0)$ & $63(16.4)$ & $13(11.7)$ \\
\hline Business & $30(6.1)$ & $26(6.8)$ & $4(3.6)$ \\
\hline Building services & $19(3.8)$ & $16(4.2)$ & $3(2.7)$ \\
\hline Transport services & $13(2.6)$ & $9(2.4)$ & $4(3.6)$ \\
\hline Domestic services & $11(2.2)$ & $10(2.6)$ & $1(0.9)$ \\
\hline Others & $71(14.4)$ & $61(15.9)$ & $13(11.7)$ \\
\hline \multicolumn{4}{|l|}{ Origin } \\
\hline Capital of the state of MS & $367(74.3)$ & $279(72.9)$ & $88(79.3)$ \\
\hline Inland MS cities & $124(25.1)$ & $101(26.4)$ & $23(20.7)$ \\
\hline Other states & $3(0.6)$ & $3(0.7)$ & - \\
\hline \multicolumn{4}{|l|}{ Place of birth } \\
\hline Capital of the state of MS & $86(19.9)$ & $68(20.9)$ & $18(17.0)$ \\
\hline Inland MS cities & $206(47.7)$ & $157(48.1)$ & $49(46.2)$ \\
\hline Other states & $140(32.4)$ & $101(31.0)$ & $39(36.8)$ \\
\hline Ignored & $62(12.6)$ & $57(14.9)$ & $5(4.5)$ \\
\hline
\end{tabular}

* Age of death. 
The average age of participants during therapy was lower than that identified in studies conducted in countries in Europe (63 years), North America (62 years), and Japan (61.5 years) (Hecking et al., 2014; Mclntyre et al., 2017; Murray et al., 2018). However, the average age was higher than that described in national studies, which identified average ages of 48.5, 49, and 51 years (Santos et al., 2018; Oliveira, Da Silva, Ferreira, \& Skalinski, 2015; Oliveira Jr, Formiga, \& Alexandre, 2014).

The number of HD patients aged 60 years and over is similar to the results of European and North American studies, in which this age group is the majority among HD patients. The results of this study corroborate evidence that the risk of CRF increases simultaneously with age (Liyanage et al., 2015; Denic et al., 2017).

It was observed that the number of male HD participants was similar to results identified in Brazilian (57.2\%) and international (59\%) studies by Hecking et al. (2014) and Marinho, Penha, Silva, and Galvão (2017), respectively. It is believed that progression to CRF occurs more quickly in men than in women, and that risk factors such as age at the start of treatment for CKD, body mass index, and plasma glucose levels may contribute to progression to the most severe stage of CKD (Neugarten, Acharya, \& Silbiger, 2000; Eriksen \& Ingebretsen, 2006). Additionally, it has been observed that males tend to avoid seeking health care, which can delay the diagnosis of CKD and lead to silent progression of CKD to the final stage of the disease (Richardson \& Smith, 2011). According to the Brazilian Ministry of Health (2020), in all Brazilian capitals, there is a greater number of men than women who tend to neglect drug treatments for chronic diseases considered as basic diseases for CRF such as SAH and diabetes mellitus.

IRC in Brazil affects economically active individuals, which leads to social expenses resulting from premature retirement, in addition to expenses with HD, hospitalizations, and drug treatments (Teixeira, Lopes, Silva, \& Santos, 2015). Research participants in this study are included in this scenario, as 35.8\% (97/271) of the total retirees were prematurely retired. A study by Santos et al. (2018) identified that $65.8 \%$ of the HD patients were retired, with $46.6 \%$ of these being premature retirements.

Our findings regarding the marital situation of HD patients confirm data observed in other studies, specifically that the majority of patients on HD have a stable union, a finding that can be considered a positive point in relation to the emotional health of the patients (Guerra-Guerrero, Sanhueza-Alvarado, \& Cáceres-Espina, 2012; Oliveira Jr et al., 2014; Spigoloni et al., 2018).

The low level of education identified among HD patients may represent a characteristic of the Brazilian population that seeks public health services, since the HD sector where the research was conducted is mainly aimed at patients in the Brazilian public health service. Additional studies carried out in other Brazilian states have confirmed the low level of education among this population (Oliveira Jr et al., 2014; Teixeira et al., 2015; Santos et al., 2018; Spigoloni et al., 2018). However, low education should also be considered as a complication towards understanding the guidelines for treatment of underlying diseases, understanding CKD and its stages, and adhering to treatment, thereby aiding the progression to CRF (Frazão, Ramos, \& Lira, 2011; Kautzky-Willer, Donner, Jensby, \& Rieder, 2012; Teixeira et al., 2015). Still, with regard to education, it was observed that $23.3 \%(115 / 494)$ of the participants did not have this information described in their medical records. Incomplete medical records, whether due to lack of administrative or clinical information, compromise the quality of health services and hinder financial and technical analysis as well as the use and quality of data for scientific research (Zunta \& Lima, 2018; Sungur, Sonğur, Çiçek, \& Top, 2019).

As for comorbidities, the majority (59.5\%) of patients suffered two or more comorbidities, mainly SAH (84.8\%) and DM (47.6\%) (Table 2). It was also observed that 2.4\% (12/494) of the total sample did not present with any comorbidities. 
Table 2. Identification of comorbidities among hemodialysis patients $(2016-2018)(\mathrm{n}=482)$.

\begin{tabular}{|c|c|c|c|}
\hline Comorbidities & $\begin{array}{l}\text { Total } \\
\text { n (\%) }\end{array}$ & $\begin{array}{l}\text { Alive }(\mathrm{n}=\mathbf{3 8 3}) \\
\text { n (\%) }\end{array}$ & $\begin{array}{l}\text { Deaths }(\mathrm{n}=111) \\
\text { n }(\%)\end{array}$ \\
\hline \multicolumn{4}{|c|}{ Number of comorbidities } \\
\hline 1 & $188(38.1)$ & $152(39.7)$ & $36(32.4)$ \\
\hline 2 & $184(37.2)$ & $144(37.6)$ & $40(36.0)$ \\
\hline 3 & $80(16.2)$ & $58(15.1)$ & $22(19.8)$ \\
\hline 4 & $24(4.9)$ & $17(4.4)$ & $7(6.3)$ \\
\hline 5 & $5(1.0)$ & $2(0.5)$ & $3(2.7)$ \\
\hline 6 & $1(0.2)$ & $0(0.0)$ & $1(0.9)$ \\
\hline \multicolumn{4}{|c|}{ Description of comorbidities } \\
\hline Hypertension & $419(84.8)$ & $336(87.7)$ & $92(82.9)$ \\
\hline Diabetes & $235(47.6)$ & $178(46.5)$ & $57(51.4)$ \\
\hline Cardiac problems & $63(12.8)$ & $39(10.2)$ & $24(21.6)$ \\
\hline Depression & $34(6.9)$ & $26(6.8)$ & $8(7.2)$ \\
\hline Obesity & $25(5.1)$ & $13(3.4)$ & $12(10.8)$ \\
\hline Neoplasm & $20(4.0)$ & $11(2.9)$ & $9(8.1)$ \\
\hline Prostatic hyperplasia & $12(2.4)$ & $11(2.9)$ & $1(0.9)$ \\
\hline Lupus & $11(2.2)$ & $10(2.6)$ & $1(0.9)$ \\
\hline Circulatory disorders & $9(1.8)$ & $7(1.8)$ & $2(1.8)$ \\
\hline Hypothyroidism & $8(1.6)$ & $6(1.6)$ & $2(1.8)$ \\
\hline Hyperparathyroidism & $6(1.2)$ & $2(0.5)$ & $4(3.6)$ \\
\hline Hyperthyroidism & $4(0.8)$ & $4(1.0)$ & $0(0.0)$ \\
\hline Epilepsy & $4(0.8)$ & $2(0.5)$ & $2(1.8)$ \\
\hline Dyslipidemia & $3(0.6)$ & $2(0.5)$ & $1(0.9)$ \\
\hline Schizophrenia & $3(0.6)$ & $3(0.8)$ & $0(0.0)$ \\
\hline Osteoporosis & $3(0.6)$ & $2(0.5)$ & $1(0.9)$ \\
\hline Breathing problems & $3(0.6)$ & $0(0.0)$ & $3(2.7)$ \\
\hline
\end{tabular}

The diagnosis of positive serology for hepatitis $\mathrm{C}$ was found in $2.8 \%(14 / 494)$ of the sample, comprising nine living participants $(2.3 \%)$ and five participants who died (4.5\%). Hepatitis B was observed in only one participant in the living group $(0.3 \%)$. HIV positive serology was identified in three participants $(0.6 \%)$, comprising two living participants $(0.5 \%)$ and one participant in the death group $(0.9 \%)$. Hepatopathy and renal lithiasis were each identified in $0.4 \%$ (2/494) of the participants. Parkinson's disease, arthritis, neurosyphilis, purpura, Sjögren's syndrome, conversion syndrome, and pleural tuberculosis were each observed in $0.2 \%(1 / 494)$ of the participants.

Most patients started HD through a CVC $(83.3 \%)$, which was maintained for $43.8 \%$ of the treatment time. The values found regarding the use of CVCs, both at the onset of and throughout treatment, are above those found in the United States and some European countries, and are far from those indexes of countries with low mortality rates, such as Japan and Russia, where less than 10\% of HD patients use CVCs during HD treatment (Xue et al., 2013; Robinson et al., 2016; USRDS, 2018). In addition, patients starting HD using a CVC are generally associated with late diagnoses that consequently lead to emergency HD. The use of CVCs may also be related to the training and qualifications of the medical team, since the technical quality of these professionals can affect the success and survival of an arteriovenous fistula (AVF) (Hecking et al., 2014).

The results regarding adherence showed that, of the 103 participants analyzed, 54 were considered non-adherent to the treatment $(52.4 \%)$. Of these patients, $14(13.6 \%)$ died during the research period, representing $56 \%$ of the total deaths in the analyzed sample in relation to adherence. Among the non-adherent participants who died, the age 
group of 60 years or more was identified as the age group containing the highest number of occurrences $(9 / 14$; $64.3 \%)$.

The group of participants aged between 30 and 39 years contained the highest percentage of non-adherent patients, in which eight of the 12 participants were classified as non-adherent (66.6\%). A total of $74 \%(40 / 54)$ of the non-adherent participants were non-white, 51.8\% were single (28/54), and 57.4\% (31/54) had a low level of education. Additionally, among the group of non-adherent participants, it was identified that $79.6 \%(43 / 54)$ of them had two or more comorbidities and $44.4 \%(24 / 54)$ had three or more comorbidities.

Our results regarding adherence to HD sessions are higher than those reported in a study by Tohme et al. (2017), in which $23 \%$ of the patients missed three or more HD sessions in one year of treatment. Various aspects influence treatment adherence, including the chosen therapy modality as well as a patient's family support, relationship with their health team, socioeconomic conditions, and access to health care (Maldaner, Beuter, Brondani, Budó, \& Pau-Letto, 2008; Guerra-Guerrero et al., 2012; Lins, Santo, Fuly, \& Garcia, 2013).

Table 3 indicates that there was no association between adherence to HD sessions and the variables of gender ( $\mathrm{p}=$ $0.516)$, color $(\mathrm{p}=0.358)$, age $(\mathrm{p}=0.521)$, marital status $(\mathrm{p}=0.242)$, comorbidities $(\mathrm{p}=0.964)$, and death $(\mathrm{p}=$ $0.681)$.

Table 3. Relationship between adherence to hemodialysis and sociodemographic characteristics, clinical characteristcs, and death $(\mathrm{n}=103)$

\begin{tabular}{lccc}
\hline \multirow{2}{*}{ Variables } & \multicolumn{2}{l}{ Adherence } & \multirow{2}{*}{ P value } \\
\cline { 2 - 3 } & No & & \\
\hline Gender, $\mathbf{n}(\%)$ & $31(55.4)$ & $25(44.6)$ & 0.516 \\
Male & $23(48.9)$ & $24(51.1)$ & \\
Female & & & \\
\hline Race, $\mathbf{n}(\%)$ & $40(50.0)$ & $40(50.0)$ & 0.358 \\
Not white & $14(60.9)$ & $9(39.1)$ & \\
White & $54.25 \pm 2.19$ & $56.4 \pm 2.29$ & 0.521 \\
\hline Age (years), mean \pm standard error of the mean Marital situation, $\mathbf{n}$ & & \\
(\%) & $26(59.1)$ & $18(40.9)$ & 0.242 \\
Stable union & $28(47.5)$ & $31(52.5)$ & \\
Single & $2.5 \pm 0.16$ & $2.48 \pm 0.16$ & 0.964 \\
\hline Number of comorbidities, mean \pm standard error of the mean & & & \\
Death, $\mathbf{n}(\%)$ & $40(51.3)$ & $38(48.7)$ & 0.681 \\
No & $14(56.0)$ & $11(44.0)$ & \\
Yes & &
\end{tabular}

It was identified that 78 of the 494 participants were enrolled for kidney transplantation (15.8\%). Of these, five patients died $(6.4 \%)$ before transplantation. Participants aged between 30 and 39 years were the majority among those enrolled (30.7\%) while the patients at the age of 60 or over were the minority $(5.0 \%)$.

Among the contraindications to transplant are active coronary disease; cardiopulmonary disease; active use of illicit substances; active local or systemic infections; obesity; post-transplant life expectancy <5 years; decompensated cirrhosis; poorly controlled psychiatric illness; malignancy; and non-adherence to prescribed therapies (Virmani \& Asch, 2020).

With regard to drug therapy, on average, each participant used $18.91 \pm 0.825$ drugs daily (minimum five and maximum 39). The average number of daily medications was higher than those found in previous studies by Manley, Garvin, and Drayer (2004) and Mclntyre et al. (2017), which identified an average of $12.3 \pm 5.2$ and 13.4 \pm 4.3 medications, respectively. Polypharmacy among this population is needed to manage comorbidities, declines in renal function, infections, and the side effects inherent to HD treatment (Tandon, Sinha, \& Agarwal, 2013; Chen et al., 2015; Pham et al., 2017; Vilay, 2019). However, 96.0\% of individuals who use five or more medications 
have some risks associated with drug-related problems (Nusair et al., 2020).

The distribution of the 222 drugs prescribed to the 494 patients with CRF during the study period is shown in Table 4, according to their ATC classification (Anatomical Therapeutic Chemical Code).

Table 4. Distribution of drugs prescribed to patients with CRF, according to the ATC classification $(n=222)$

\begin{tabular}{lrr}
\hline Anatomical Therapeutic Chemical Group Level I & $\mathbf{n}$ & $\mathbf{\%}$ \\
\hline A - Alimentary tract and metabolism & 36 & 16.2 \\
B - Blood and blood forming organs & 12 & 5.4 \\
C - Cardiovascular system & 33 & 14.9 \\
D - Dermatologicals & 28 & 12.6 \\
G - Genitourinary system and sex hormones & 3 & 1.3 \\
H - Systemic hormonal preparations, excluding sex hormones and insulins & 11 & 5.0 \\
J - Anti-infective for systemic use & 25 & 11.2 \\
L - Antineoplastic and immunomodulating agents & 1 & 0.5 \\
M - Musculo-skeletal system & 7 & 3.2 \\
N - Nervous system & 28 \\
P - Antiparasitic products, insecticides, and repellents & 12.6 \\
R - Respiratory system & 3 & 1.3 \\
S - Sensory organs & 23 & 10.4 \\
V - Various & 9 & 4.1
\end{tabular}

Within the anatomical group alimentary tract and metabolism, anti-ulcer medications were the majority (53.4\%). Among patients who used anti-ulcer agents, the use of Omeprazole was predominant (46.6\%). Although this class of anti-ulcer agents is frequently prescribed, the safety of using proton pump inhibitors (PPIs) has been questioned in recent years. Authors attribute the use of PPIs with an increased risk of contracting pneumonia (Gulmez et al., 2007; De Jager et al., 2012; Chen et al., 2015). According to these authors, the medication's mechanisms of action, which decreases gastric volume, allows colonization and excessive growth of bacteria in the upper gastrointestinal tract, which increases a patient's susceptibility to infection by these bacteria.

Among the drugs in the blood and blood forming organs group, antihypertensive drugs are widely used among HD patients. Data collected in the current study show the use of at least one antihypertensive in $86.4 \%$ of participants, which is a lower frequency than that described by Bakris, Burkart, Weinhandl, Mccullough, and Kraus (2016), who reported that $70 \%$ of individuals used antihypertensives. The main antihypertensive drugs used by the participants were amlodipine (64.1\%), losartan (41.7\%), and atenolol (33.9\%). Hypertension in HD patients is multifactorial; the main causes include high peripheral resistance and hypervolemia (Tandon et al., 2013).

In the nervous system anatomical group, the use of opioid analgesics was identified in $50.5 \%$ of the participants, which is similar to results described by ESRDS (2018) that demonstrated 49\% of North American individuals on HD using this class of analgesics. However, these values are higher than those reported by KDIGO (2013), in which $37.2 \%$ of the HD patients used some type of opioid. The main opioid analgesics used by the study participants were tramadol (40.8\%) and the combination of paracetamol plus codeine (31.1\%).

When prescribing analgesics, factors such as the type and severity of pain, the duration of treatment, and potential interactions with drugs already in use by the patient should be considered. Opioids are commonly used to treat visceral pain with deep and poorly located characteristics (Pham et al., 2009).

Some aspects need to be considered regarding the prescription of this therapeutic class for HD patients, including the possibility that gastrointestinal side effects related to the use of opioid analgesics are more pronounced in patients with CRF, as well as alterations of the pharmacokinetics of these drugs in this population. It requires monitoring for signs of toxicity with corresponding adjustments to dose (Pham et al., 2009; Pham et al., 2017; Yalamarti \& Janice Lee, 2019).

Another point to be considered when prescribing analgesics to this population is that the use of tramadol is often 
associated with serotonin syndrome (Baldo \& Rose, 2020). In fact, tramadol in combination with other serotonergic drugs may be the major cause of serotonin syndrome. Serotonergic drugs include selective serotonin reuptake inhibitor antidepressants and tricyclic antidepressants (Rickli, Liakoni, Hoener, \& Liechti, 2018; Baldo, 2018). In this study, the use of these two classes of antidepressants, mainly fluoxetine and amitriptyline, were observed in $45.3 \%$ of the participants.

With regards to the anatomical group of general anti-infectives for systemic use, Hui et al. (2017), in a study conducted in Australia, reported the use of antimicrobials in 55.3\% of HD patients. Meanwhile, an American report identified the use of antimicrobials in $57.9 \%$ of the HD population (USRDS, 2018). In the current study, it was identified that antimicrobials were used by $84.5 \%$ of the participants, which deserves attention both for being an indicator of a high rate of infection and for the peculiarities that involve the appropriate dose for this population. In HD patients, the plasma concentration of antimicrobials may change due to alterations in the clearance of these drugs during the HD procedure (Matzke et al., 2011). The oral antimicrobials with the highest number of prescriptions were ciprofloxacin (61.2\%), amoxicillin (35.9), and metronidazole (13.9\%). The most prescribed intravenous antimicrobials were vancomycin (59.2\%), ceftazidime (57.2\%), and amikacin (21.4\%).

Some factors must be considered in relation to increased clearance during HD sessions. Medicines with lower molecular weights, lower volumes of distribution, and less binding to plasma proteins may undergo greater clearance. In addition to these factors, the adequacy of the dose of each medication must take into account the understanding of the pharmacokinetic principles and the patient's clinical situation (Matzke et al., 2011). Inadequate doses of antimicrobials can harm patients; high doses may increase plasma concentrations and toxicity while low doses may not provide adequate efficacy, thereby increasing the risk of bacterial resistance and death (Vilay, 2019).

Medicines used to treat hyperkalaemia and hyperphosphatemia were taken by $78.1 \%$ of the study participants. These results do not differ significantly from the results of a study on a North American population, in which $71.5 \%$ of the patients used phosphate chelators (USRDS, 2018). In the Brazilian Dialysis Survey (2017), less use of these drugs was estimated among HD patients in Brazil (64\%) (Thomé et al., 2019).

The use of erythropoietin and iron for the treatment of anemia was observed in $70.7 \%$ and $66 \%$ of participants, respectively. Thomé et al. (2019) identified the use of erythropoietin in 74\% and iron in 53\% of individuals.

Of the total medical records analyzed (494), it was observed that 111 (22.5\%) patients died. Of these deaths, 60.4\% occurred in the age group of 60 years or greater, while $18.0 \%$ occurred in the age group of 50-59 years.

Stratifying by age group, mortality was $21.7 \%$ (5/23) among participants aged 18 to 29 years; 7.7\% (4/52) among those aged 30 to $39 ; 20.3 \%$ (15/74) among those 40 and 49 years old; $18.5 \%$ (20/108) among those between 50 and 59 years; and $28.3 \%(67 / 237)$ among participants aged $\geq 60$ years.

Evaluation of the clinical outcome of death demonstrated a relationship between this variable and age (student's t-test, $\mathrm{p}=0.003$ ), with greater age being observed among the participants who died. The average age at death was $60.34 \pm 1.44$ years old. There was also a relationship between death and the number of comorbidities (student's t-test, $\mathrm{p}=0.009)$, with a greater number of comorbidities associated with a higher percentage of death (Table 5). According to Rteila et al. (2020), comorbidities are related to an increased risk of bloodstream infections among patients on HD.

A significant difference was also noted between the means of vascular access, specifically CVC or AVF, and death during treatment $(\mathrm{p}=0.025)$, with $\mathrm{CVC}$ access associated with a higher percentage of death among participants $(60.34 \pm 9.17 \%)$. Countries with low mortality rates, such as Russia and Japan, have a high rate of patients receiving HD via AVF. Approximately $80 \%$ of Japanese patients initiating HD undergo successful AVF preparation prior to their first session, reaching more than $90 \%$ of patients using AVF during HD at all dialysis centers. Like Japan, Russia also has a majority (92\%) of patients using AVF during HD (Pisoni, Zepel, Port, \& Robinson, 2015). 
Table 5. Relationship between death and sociodemographic and clinical characteristics of patients on hemodialysis $(\mathrm{n}=111)$

\begin{tabular}{lccc}
\hline \multirow{2}{*}{ Variables } & \multicolumn{2}{c}{ Death } & Yes \\
\cline { 2 - 3 } & No & & \\
\hline Gender, $\mathbf{n}(\%)$ & $167(77.3)$ & $49(22.7)$ & 0.919 \\
Male & $216(77.7)$ & $62(22.3)$ & \\
Female & & & \\
\hline Race, $\mathbf{n}(\%)$ & $305(79.8)$ & $77(20.2)$ & 0.021 \\
Not White & $77(69.4)$ & $34(30.6)$ & \\
White & $55.61 \pm 0.75$ & $60.34 \pm 1.44$ & 0.003 \\
\hline Age (years), mean \pm standard error of the mean Marital Situation, & & & \\
n (\%) & $206(80.9)$ & $49(19.2)$ & 0.066 \\
Stable union & $177(73.9)$ & $62(26.1)$ & \\
Single & & & \\
\hline Venous access, mean \pm standard error of the mean & $60.96 \pm 4.31$ & $39.65 \pm 9.17$ & 0.025 \\
Fistula & $39.03 \pm 4.31$ & $60.34 \pm 9.17$ & 0.025 \\
Central venous catheter & $1.80 \pm 0.04$ & $2.08 \pm 0.10$ & 0.009 \\
\hline Number of comorbidities, mean \pm standard error of the mean & & & \\
\hline
\end{tabular}

Non-white individuals had a higher number of deaths in the total sample, however, a higher prevalence of deaths was observed among white patients $(30.6 \%$, chi-square test $p=0.021)$, with a mean age of $59.2 \pm 2.8$ years. Of the 112 white participants in treatment, 34 died while, among non-whites, 76 of the 377 participants died (20.2\%).

According to Kucirka et al. (2011), white HD patients aged 50 years or older have a higher mortality when compared to non-white patients of the same age. Buckalew Jr and Freedman (2010) suggest that genetic factors may be related to the differences in survival observed between African Americans and whites. In a study by Ku et al. (2019), the authors suggest that a higher survival among black patients may be related to white patients having a worse clinical condition when starting HD.

With regard to the time between the first HD session and death, more than half $(54.1 \%)$ of the patients died during the first two years of HD treatment. Of these deaths, $31.5 \%$ of the $54.1 \%$ occurred in the first 12 months of therapy. According to research carried out in the United Kingdom, the risk of infection appears to be greatest at the beginning of treatment, especially within the first two months of $\mathrm{HD}$, and approximately $50 \%$ of all bacteremias identified in the first year of treatment occurred before the 67th day of HD (Murray et al., 2018). A detailed distribution of the time between the first HD session and death, as well as the cause of death, is shown in Table 6 .

A study by Pippias et al. (2016) identified that $31.4 \%$ of individuals on HD died from cardiovascular causes, $13.9 \%$ from infections, $6.9 \%$ from neoplasms, $20.3 \%$ from other causes, and $27.5 \%$ from unknown causes or causes not reported. Similar data were described in a report presented by the USRDS (2018), in which $31 \%$ of individuals on HD died from cardiovascular causes, $8 \%$ from infections, $3 \%$ from neoplasms, $32 \%$ from other causes, and $26 \%$ from unknown or unreported causes. A patient's clinical condition contributes to this outcome, as do other chronic comorbidities, immune status, tobacco use, nutritional status, and skin integrity (Rteila et al., 2020).

With regards to infections, catheter exposure, handling, and failure in basic aseptic principles, such as hand hygiene and use of personal protective equipment, are factors that can potentially increase the risk of infections in HD patients (Lins et al., 2013).

Survival was significantly related to age $(\mathrm{p}=0.001)$, with advanced age being associated with a higher risk of death (Table 7). Similar data was reported by Teixeira et al. (2015), in which the variable of age was shown to have a statistically significant influence on the survival of patients, with $p=0.001$. 
Table 6. Distribution of patients according to the cause of death and the time between the first hemodialysis and death $(\mathrm{N}=111)$

\begin{tabular}{ll}
\hline Variables & Total n (\%) \\
\hline Time between 1st hemodialysis treatment and death (months) & $35(31.5)$ \\
$0-12$ & $25(22.6)$ \\
$13-24$ & $14(12.6)$ \\
$25-36$ & $11(9.9)$ \\
$37-48$ & $6(5.4)$ \\
$49-60$ & $20(18.0)$ \\
$>60$ & $36.99 \pm 3.91$ \\
\hline Mean survival time (months, mean \pm standard error of the mean) & 22.5 \\
\hline Crude mortality rate (2016-2018) & \\
\hline Cause of death & $63(56.8)$ \\
Septic shock & $8(7.2)$ \\
Cardiac arrhythmia & $8(7.2)$ \\
Respiratory failure & $6(5.4)$ \\
Cardiogenic shock & $4(3.6)$ \\
Cerebral hemorrhage & $3(2.7)$ \\
Hemorrhagic shock & $3(2.7)$ \\
Brain stroke & $2(1.8)$ \\
Hypovolemic shock & $2(1.8)$ \\
Acute myocardial infarction & $2(1.8)$ \\
Neoplasm & $2(1.8)$ \\
Acute lung edema & $8(7.2)$ \\
Undetermined cause & \\
\hline
\end{tabular}

Table 7. Relationship between survival and gender and age in hemodialysis patients

\begin{tabular}{lccc}
\hline Variables & P value* $^{*}$ & Odds ratio & 95\% confidence interval \\
\hline Gender & 0.137 & 1.33 & $0.91-1.95$ \\
Age & 0.001 & 1.02 & $1.01-1.03$ \\
\hline
\end{tabular}

*P value in the Cox regression test.

The total sample of HD patients had a greater number of males (56.3\%), and this trend was also observed among the patients who died (55.9\%). Despite this, greater survival was observed among male participants (Figure 1). 


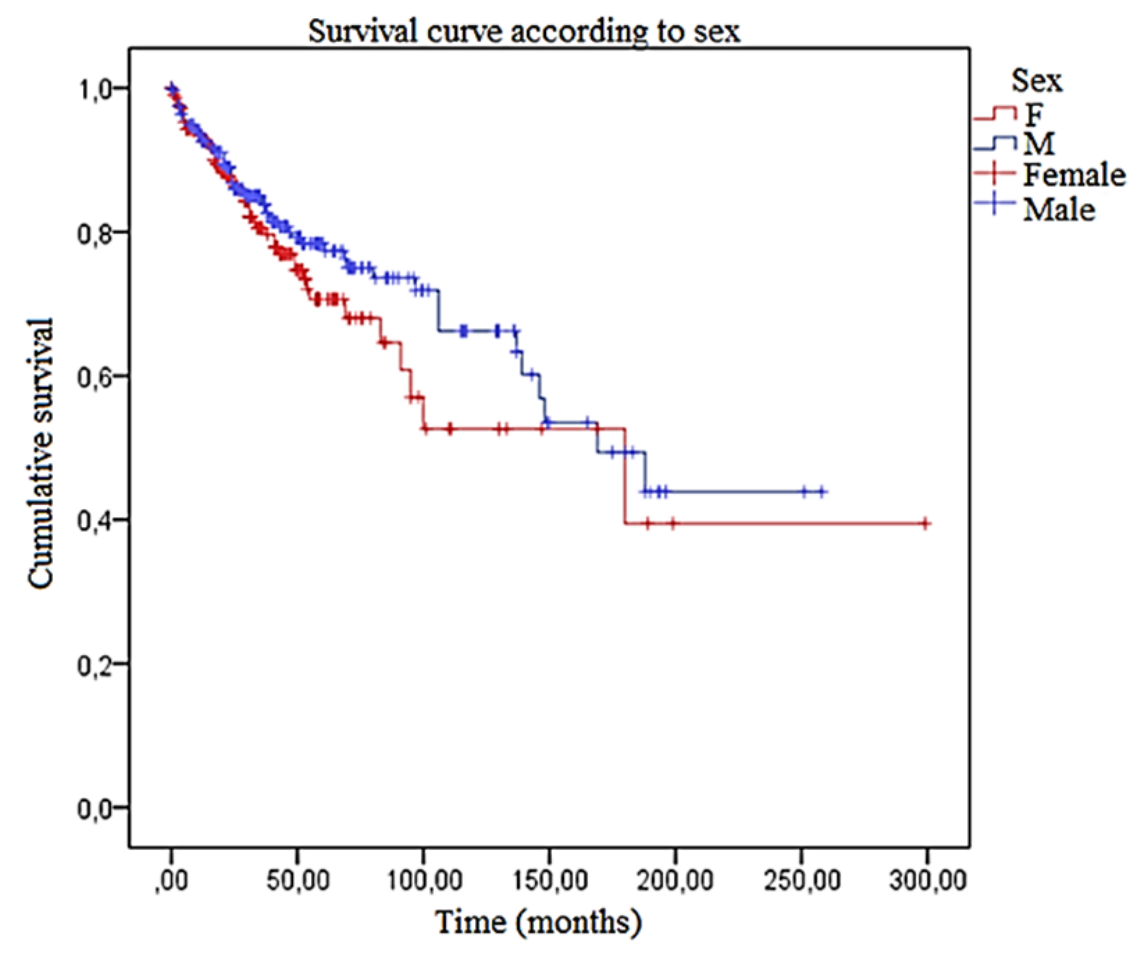

Figure 1. Survival curve according to sex according to the Kaplan Meier model. Campo Grande - MS, 2020

It has been observed that, within the general population, a significant difference in survival exists between the sexes. In general (several countries and different cultures) women have longer survivals. In the 20th century, it has been estimated that the difference in life expectancy between men and women was approximately four years, with variations existing between different countries. In the last three decades, the difference has been approximately one year (Alberts, Archie, Gesquiere, Altmann, \& Christensen, 2014). According to Hecking et al. (2014), the lower glomerular filtration rate found among female HD patients, along with the higher risk of mortality associated with cardiovascular diseases among women, may explain this outcome.

The main limitation of the study was the lack of organization in the file of patients' medical records, which hindered data collection. Still, the results reflect the reality of chronic kidney patients on HD being treated in the Brazilian public health service, making it necessary to know the scenario experienced by patients in private health services.

\section{Conclusion}

Analysis of the scenario of chronic kidney patients on HD shows that this population is composed mainly of non-white males with low education as well as young people. Hypertension and diabetes are prevalent comorbidities and the number of comorbidities seems to be related to the prognosis of the disease.

The use of a CVC is practical in this environment, which may also influence the chance of death. Non-adherence to HD sessions was observed in a representative number of patients. The outcome of death occurred in greater numbers in white patients, as well as within the first 24 months of HD treatment, mainly in the first 12 months. Age seems to influence the survival of this population.

HD patients are polymedicated, which suggests the need for pharmacotherapeutic follow-up, both for the prevention of medication-related problems, as well as for the suggestion and discussion of discontinuation of possible medications.

\section{Acknowledgments}

The authors thank the Coordenação de Aperfeiçoamento de Pessoal de Nível Superior - Brasil (CAPES) and Universidade Federal de Mato Grosso do Sul (UFMS). This work was supported in part by these institutes.

\section{Competing Interests Statement}

The authors declare that there are no competing or potential conflicts of interest. 


\section{References}

Albertus, P., Morgenstern, H., Robinson, B., \& Saran, R. (2016). Risk of end-stage renal disease in the United States. American Journal of Kidney Diseases, 68(6), 862-872. https://doi.org/10.1053/j.ajkd.2016.05.030

Alberts, S. C., Archie, E., Gesquiere, L., Altmann, J., \& Christensen, K. (2014). The male-female health-survival paradox: a comparative perspective on sex differences in aging and mortality. In M., Weinstein, \& M. A., Lane, (Eds.), Sociality, hierarchy, health: comparative biodemography (pp. 337-361). Washington, D.C: National Academies Press.

Alcalde, P. R., \& Kirsztajn, G. M. (2018). Gastos do Sistema Único de Saúde brasileiro com doença renal crônica. Brazilian Journal of Nephrology, 40(2), 122-129. https://doi.org/10.1590/2175-8239-jbn-3918

Bakris, G. L., Burkart, J. M., Weinhandl, E. D., Mccullough, P. A., \& Kraus, M. A. (2016). Intensive Hemodialysis, Blood Pressure, and Antihypertensive Medication Use. American Journal of Kidney Diseases, 68(5)(suppl 1), 15-23. https://doi.org/10.1053/j.ajkd.2016.05.026

Baldo, B. A. (2018). Opioid analgesic drugs and serotonin toxicity (syndrome): mechanisms, animal models, and links to clinical effects. Archives of Toxicology, 92, 2457-2473. https://doi.org/10.1007/s00204-018-2244-6

Baldo, B. A., \& Rose, M. A. (2020). The anaesthetist, opioid analgesic drugs, and serotonin toxicity: a mechanistic and clinical review. British Journal of Anaesthesia, 124(1), 44-62. https://doi.org/10.1016/j.bja.2019.08.010

Bello, A. K., Alrukhaimi, M., Ashuntantang, G. E., Basnet, S., Rotter, R. C., Douthat, W. G., ... \& Moe, O. (2017). Complications of chronic kidney disease: current state, knowledge gaps, and strategy for action. Kidney International Supplements, 7, 122-129. https://doi.org/10.1016/j.kisu.2017.07.007

Brasil. Ministério da Saúde. Secretaria de Vigilância em Saúde. Departamento de Análise em Saúde e Vigilância de Doenças Não Transmissíveis. Vigitel Brasil 2019: vigilância de fatores de risco e proteção para doenças crônicas por inquérito telefônico: estimativas sobre frequência e distribuição sociodemográfica de fatores de risco e proteção para doenças crônicas nas capitais dos 26 estados brasileiros e no Distrito Federal em 2019. Retrieved from http://bvsms.saude.gov.br/bvs/publicacoes/vigitel_brasil_2019_vigilancia_fatores_risco.pdf

Buckalew Jr, V. M., \& Freedman, B. I. (2010). Reappraisal of the Impact of Race on Survival in Patients on Dialysis. American Journal of Kidney Diseases, 55(6), 1102-1110. https://doi.org/10.1053/j.ajkd.2009.10.062

Chen, C. H., Lin, H. C., Lin, H. L., Lin, Y. T., Chou, J. M., Hsu, S. P., \& Fung, C. P. (2015). Proton pump inhibitor usage and the associated risk of pneumonia in patients with chronic kidney disease. Journal of Microbiology, Immunology and Infection, 48, 390-396. https://doi.org/10.1016/j.jmii.2013.10.004

De Jager, C. P. C., Wever, P. C., Gemen, E. F. A., Van Oijen, M. G. H., Van Gageldonk-Laferber, A. B., Siersema, P. D., ... \& Laheij, R. J. F. (2012). Proton pump inhibitor therapy predisposes to community-acquired Streptococcus pneumoniae pneumonia. Alimentary Pharmacology \& Therapeutics, 36, 941-949. https://doi.org/10.1111/apt.12069

Denic, A., Lieske, J. C., Chakkera, H. A., Poggio, E. D., Alexander, M. P., Singh, P., .. \& Rule, A. D. (2017). The substantial loss of nephrons in healthy human kidneys with aging. Journal of the American Society of Nephrology, 28(1), 313-320. https://doi.org/10.1681/ASN.2016020154

European Renal Association - European Dialysis and Transplant Association (ERA-EDTA). ERA-EDTA Registry Annual Report 2017. Department of Medical Informatics, Amsterdam, The Netherlands, 2019.

Eriksen, B. O., \& Ingebretsen, O. C. (2006). The progression of chronic kidney disease: a 10-year population-based study of the effects of gender and age. Kidney international, 69, 375-382. https://doi.org/10.1038/sj.ki.5000058

Fleishman, T. T., Dreiher, J., \& Shvartzman, P. (2018). Pain in Maintenance Hemodialysis Patients: A Multicenter Study. Journal of Pain and Symptom Management, 56(2), 178-184. https://doi.org/10.1016/j.jpainsymman.2018.05.008

Foley, R. N., Chen, S. C., Solid, C. A., Gilbertson, D. T., \& Collins, A. J. (2014). Early mortality in patients starting dialysis appears to go unregistered. Kidney international, 86, 392-398. https://doi.org/10.1038/ki.2014.15

Frazão, C. M. F.Q., Ramos, V. P., \& Lira, A. L. B. C. (2011). Qualidade de vida de pacientes submetidos à hemodiálise. Revista Enfermagem UERJ, 19(4), 577-582.

Guerra-Guerrero, V., Sanhueza-Alvarado, O., \& Cáceres-Espina, M. (2012). Quality of life in people with chronic 
hemodialysis: association with sociodemographic, medical-clinical and laboratory variables. Revista Latino-Americana de Enfermagem, 20(5), 838-846. https://doi.org/10.1590/S0104-11692012000500004

Gulmez, S. E., Holm, A., Frederiksen, H., Jensen, T. G., Pedersen, C., \& Hallas J. (2007). Use of proton pump inhibitors and the risk of community-acquired pneumonia: a population-based case- control study. Archives Internal Medicine, 167, 950-955. https://doi.org/10.1001/archinte.167.9.950

Hanudel, M. R., Froch, L. F., Gales, B., Jüppner H., \& Salusky, I. B. (2017). Fractures and Osteomalacia in a Patiente Treated With Frequent Home Hemodialysis. American Journal of Kidney Diseases, 70(3), 445-448. https://doi.org/10.1053/j.ajkd.2017.03.015

Hecking, M., Bieber, B. A., Ethier, J., Kautzky-Willer, A., Sunder-Plassmann, G., Säemann, M. D., ... Port, F. K. (2014). Sex - Specific Differences in Hemodialysis Prevalence and Practices and Male-to-Female Mortality Rate: The Dialysis Outcomes and Practice Pattern Study (DOPPS). Plos One, 11(10), 1-17. https://doi.org/10.1371/journal.pmed.1001750

Hill, N. R., Fatoba, S. T., Oke, J. L., Hirst, J. A., O’Callaghan, A., Lasserson, D. S., \& Hobbs, F. D. R. (2016). Global Prevalence of Chronic Kidney Disease A Systematic Review and Meta-Analysis. Plos One, 11(7), 1-18. https://doi.org/10.1371/journal.pone.0158765

Hui, K., Nalder, M., Buising, K., Pefanis, A., Ooi, K. Y., Pedagogos, E., ... \& Kong, D. C. M. (2017). Patterns of use and appropriateness of antibiotics prescribed to patients receiving haemodialysis: An observational study. BMC Nephrology, 18, 156. https://doi.org/10.1186/s12882-017-0575-9

Jacobson, J., Ju, A., Baumgart, A., Unruh, M., O’Donoghue, D., Obrador, G., ... \& Tong, A. (2019). Patient Perspectives on the Meaning and Impact of Fatigue in Hemodialysis: A Systematic Review and Thematic Analysis of Qualitative Studies. American Journal of Kidney Diseases, 74(2), 179-192. https://doi.org/10.1053/j.ajkd.2019.01.034

Johnson, R. J., Stenvinkel, P., Jensen, T., Lanaspa, M. A., Roncal, C., Song, Z., ... \& Sánchez-Lozada, L. G. (2016). Metabolic and kidney diseases in the setting of climate change, water shortage, and survival factors. Journal of the American Society of Nephrology, 27, 2247-2256. https://doi.org/10.1681/ASN.201512131

Kautzky-Willer, A., Donner, T., Jensby, A., \& Rieder, A. (2012). Women show a closer association between educational level and hypertension or diabetes mellitus than males: a secondary analysis from the Austrian HIS. BMC Public Health, 12, 392. https://doi.org/10.1186/1471-2458-12-392

Kidney Disease: Improving Global Outcomes (KDIGO) CKD Work Group. KDIGO 2012. (2013) Clinical Practice Guideline for the Evaluation and Management of Chronic Kidney Disease. Kidney International Supplements, 3, 1-150.

Ku, E., Yang, W., Mcculloch, C. E., Feldman, H. I., Go, A. S., Lash, J., ... \& Hsu, C. (2020). Race and Mortality in CKD and Dialysis: Findings From the Chronic Renal Insufficiency Cohort (CRIC) Study. American Journal of Kidney Diseases, 75(3), 394-403. https://doi.org/10.1053/j.ajkd.2019.08.011

Kucirka, L. M., Grams, M. E., Lessler, J., Hall, E. C., James, N., Massie, A. B., ... \& Segev, D. L. (2011). Association of Race and Age With Survival Among Patients Undergoing Dialysis. American Medical Association, 306(6), 620-626. https://doi.org/10.1001/jama.2011.1127

Lins S. M. S. B., Santo, F. H. E., Fuly, P. S. C., \& Garcia T. R. (2013). Subset of ICNP® diagnostic concepts for patients with chronic kidney disease. Revista Brasileira de Enfermagem, 66(2), 180-189. https://doi.org/10.1590/S0034-71672013000200005

Liyanage, T., Ninomiya, T., Jha, V., Neal, B., Patrice, H. M., Okpechi, I., ... Perkovicet, V. (2015). Worldwide access to treatment for end-stage Kidney disease: a systematic review. Lancet, 385, 1975-1982. https://doi.org/10.1016/S0140-6736(14)61601-9

Maldaner, C. R., Beuter, M., Brondani, C. M., Budó, M. L. D., \& Pau- Letto, M. R. (2008). Fatores que influenciam a adesão ao tratamento na doença crônica: o doente em terapia hemodialítica. Revista Gaúcha de Enfermagem, 29(4), 647-53.

Manley, H. J., Garvin, C. G., \& Drayer, D. K. (2004). Medication prescribing pattems in ambulatory hemodialysis patients: Comparisons of USRD to a large not-for-profit dialysis provider. Nephrology Dialysis Tranplantation, 19, 1842-1848. https://doi.org/10.1093/ndt/gfh280

Marinho, A. W. G., Penha, A. P., Silva, M.T., \& Galvão, T. F. (2017). Prevalência de doença renal crônica em adultos no Brasil: revisão sistemática da literatura. Caderno de Saúde Coletiva, 25(3), 379-388. 
https://doi.org/10.1590/1414-462x201700030134

Matzke, G. R., Aronoff, G. R., Atkinson Jr, A. J., Bennett, W. M., Decker, B. S., Eckardt, K. U., ... \& Murray, P. (2011). Drug dosing consideration in patients with acute and chronic kidney disease-a clinical update from Kidney Disease: Improving Global Outcomes (KDIGO). Kidney International, 80, 1122-1137. https://doi.org/10.1038/ki.2011.322

Mclntyre, C., Mcquillan, R., Bell, C., \& Battistella, M. (2017). Targeted Deprescribing in an Outpatiente Hemodialysis Unit: A Quality Improvement Study to Decrease Polypharmacy. American Journal of Kidney Diseases, 70(5), 611-618. https://doi.org/10.1053/j.ajkd.2017.02.374

Muci, M. L., Tartaglione, L., Rotondi, S., Carbone, L., \& Mazzaferro, S. (2017). Relatioship between vascular access triage and clinical events in hemodialysis. Nephrology Dialysis Transplantation, 32(3), 358. https://doi.org/10.1093/ndt/gfx154.SP657

Murray, E., Eid, M., Traynor, J. P., Stevenson, K. S., Kasthuri, R., Kingsmore, D. B., \& Thomson, P. C. (2018). The first 365 days on hemodialysis: variation in the haemodialysis access journey and its associated burden. Nephrology Dialysis Transplantation, 33(7), 1244-1250. https://doi.org/10.1093/ndt/gfx380

Naghavi, M., Wang, H., Lozano, R., Davis, A., Liang, X., Zhou, M., ... \& Murray, C. J. L. (2015). Global, regional, and national age-sex specifi c all-cause and cause-specifi c mortality for 240 causes of death, 1990-2013: a systematic analysis for the Global Burden of Disease Study 2013. Lancet, 385(9963), 117-171. https://doi.org/10.1016/S0140-6736(14)61682-2

Nayana, S. A., Balasubramanian, T., Nathaliya, P. M., Nimsha Hussain, P., Mohammed Salim, K. T., \& Muhammed Lubab, P. (2017). A cross sectional study on assessment of health related quality of life among end stage renal disease patients undergoing hemodialysis. Clinical Epidemiology and Global Health, (5), 148-153. https://doi.org/10.1016/j.cegh.2016.08.005

Neugarten, J., Acharya, A., \& Silbiger, S. R. (2000). Effect of gender on the progression of nondiabetic renal disease: a meta-analysis. Journal of the American Society of Nephrology, 11, 319-329. https://doi.org/10.1681/ASN.V112319

Nusair, M. B., Al-Azzam, S. L., Arabyat, R. M., Amawi, H. A., Alzoubi, K. H., \& Rabah, A. A. (2020). The prevalence and severity of potential drug-drug interactions among adult polypharmacy patients at outpatient clinics in Jordan. Saudi Pharmaceutical Journal, 28, 155-160. https://doi.org/10.1016/j.jsps.2019.11.009

Oliveira JR, H. M., Formiga, F. F. C., \& Alexandre, C. D. S. (2014). Clinical and epidemiological profile of chronic hemodialysis patients in João Pessoa - PB. Brazilian Journal of Nephrology, 36(3), 367-374. https://doi.org/10.5935/0101-2800.20140052

Oliveira, C. S., Da Silva, E. C., Ferreira, L. W., \& Skalinski, L. M. (2015). Perfil dos pacientes renais crônicos em tratamento hemodialítico. Revista Baiana de Enfermagem, 29(1), 42-49.

Pham, P. C., Toscano, E., Pham, P. M., Pham, P. A., Pham, S. V., \& Pham, P. T. (2009). Pain management in patients with chronic kidney disease. Nephrology Dialysis Tranplantation, plus, 2(2), 111-118. https://doi.org/10.1093/ndtplus/sfp001

Pham, P. C., Khaing, K., Sievers, T. M., Pham, P. M., Miller, J. M., Pham, S. V., ... \& Pham, P. T. (2017). update on pain management in patients with chronic kidney disease. Clinical Kidney Journal, 10(5), 688-697. https://doi.org/10.1093/ckj/sfx080

Pippias, M., Jager, K. J., Kramer A., Leivestad, T., Sánchez, M. B., Caskey, F. J., ... \& Stel, V. S. (2016). The changing trends and outcomes in renal replacement therapy: data from the ERA-EDTA registry. Nephrology Dialysis Transplantation, 31, 831-841. https://doi.org/10.1093/ndt/gfv327

Pisoni, R. L., Zepel, L., Port, F. K., \& Robinson, B. M. (2015). Trends in US Vascular Access Use, Patient Preferences, and Related Practices: An Update From the US DOPPS Practice Monitor With International Comparisons. American Journal of Kidney Diseases, 65(6), 905-915. https://doi.org/10.1053/j.ajkd.2014.12.014

Rteila, A., Kazmaa, J. M., Sawdac, J. E. L., Gharamtic, A., Koubarb, S. H., \& Kanafanic, E. A. (2020). Clinical characteristics, risk factors and microbiology of infections in patients receiving chronic hemodialysis. Journal of Infection and Public Health, 13(8), 1166-1171. https://doi.org/10.1016/j.jiph.2020.01.314

Ribeiro, C. D. S., Alencar, C. S. M., Feitosa, M. C. D., \& Mesquita, M. A. S. B. (2013). Perception of patients with chronic kidney disease on hemodialysis treatment. Revista Interdisciplinar, 6(3), 36-44. 
Rickli, A., Liakoni, E., Hoener, M. C., \& Liechti, M. E. (2018). Opioid- induced inhibition of the human 5-HT and noradrenaline transporters in vitro: link to clinical reports of serotonin syndrome. British Journal of Pharmacology, 175, 532-543. https://doi.org/10.1111/bph.14105

Richardson, N., \& Smith, J. A. (2011). National men's health policies in Ireland and Australia: What are the challenges associated with transitioning from development to implementation? Public Health, 125, 424-432. https://doi.org/10.1016/j.puhe.2011.04.015

Robinson, B., Zhang, L., Morgenstern, H., Bradbury, B. D., Ng, 1. J., Mccullough, K. P., ... \& Pisoni, R. L. (2014). Worldwide, mortality is a high risk soon after initiation of hemodialysis. Kidney international; 85, 158-165. https://doi.org/10.1038/ki.2013.252

Robinson, B., Akizawa, T., Jager, K. J., Kerr, P. G., Saran, R., \& Pisoni, R. (2016). Factors affecting outcomes in patients reaching end-stage kidney disease worldwide: differences in access to renal replacement therapy, modality use, and haemodialysis practices. Lancet, 388, 294-306. https://doi.org/10.1016/S0140-6736(16)30448-2

Santos, K. K., Lucas, T. T., Glória, J. C., Pereira jr, R. C., Ribeiro, G. C., \& Lara, M. O. (2018). Perfil epidemiológico de pacientes renais crônicos em tratamento. Revista de enfermagem, 12(9), 2293-2300. https://doi.org/10.5205/1981-8963-v12i9a234508p2293-2300-2018

Saran, R., Robinson, B., Abbott, K. C., Agodoa, L. Y., Albertus, P., Ayanian, J., ... \& Shahinian, V. (2017). US Renal Data System 2016 Annual Data Report: epidemiology of kidney disease in the United States. American Journal of Kidney Diseases, 69(3), S1-S688. https://doi.org/10.1053/j.ajkd.2017.01.036

Sesso, R. C., Lopes, A. A., Thomé, F. S., Lugon, J. R., \& Martins, C. T. (2017). Inquérito Brasileiro de Diálise Crônica 2016 - Análise das tendências entre 2013 e 2016. Jornal Brasileiro de Nefrologia, 39(3), 261-266. https://doi.org/10.5935/0101-2800.20170049

Scott, I. A., Gray, L. C., Martin, J. H., Pillans, P. I., \& Mitchell, C. A. (2012). Minimizing inappropriate medications in older populations: a 10-step conceptual framework. American Journal of Medicine, 125(6), 529-537. https://doi.org/10.1016/j.amjmed.2011.09.021

Shirazian, S. (2019). Depression in patients undergoing hemodialysis: time to treat. Kidney International, 96, 1264-1268. https://doi.org/10.1016/j.kint.2019.05.017

Spigoloni, D. N., Testoni, E. F., Souza, F. O., Santos, B., Souza R. R., \& Moreira Neto, A. (2018). Diagnósticos de enfermagem de portadores de doença renal em hemodiálise: estudo transversal. Revista Brasileira de Enfermagem, 71(4), 2130-2136. https://doi.org/10.1590/0034-7167-2017-0225

Stenvinkel, P., Zoccali, C., \& Ikzler, T. A. (2013). Obesity in CKD - What should nephrologists know? Clinical Journal of the American Sciety of Nephrology, 24, 1727-1736. https://doi.org/10.1681/ASN.2013040330

Sungur, C., Sonğur, L., Çiçek, A. C., \& Top, M. (2019). Correction of patient medical record errors through a file control method. Health Policy and Technology, 8, 329-336. https://doi.org/10.1016/j.hlpt.2019.08.010

Swaminathan, S., Mor, V., Mehrotra, R., \& Trivedi, A. N. (2017). Initial Session Duration and Mortality among Incident Hemodialysis Patients. American Journal of Kidney Diseases, 70(1), 69-75 https://doi.org/10.1053/j.ajkd.2016.11.017.

Tandon, T., Sinha, A. D., \& Agarwal, R. (2013). Shorter delivered dialysis times associate with a higher and more difficult to treat blood pressure. Nephrology Dialysis Tranplantation, 28(6), 1562-1568. https://doi.org/10.1093/ndt/gfs597

Teixeira, F. I. R., Lopes, M. L. H. L., Silva, G. A. S., \& Santos, R. F. (2015). Sobrevida de pacientes em hemodiálise em um hospital universitário. Jornal Brasileiro de Nefrologia, 37(1), 64-71. https://doi.org/10.5935/0101-2800.20150010

Thomé, F. S., Sesso, R. C., Lopes, A. A., Lugon, J. R., \& Martins, C. T. (2019). Inquérito Brasileiro de Diálise $\begin{array}{lllll}\text { Crônica. Jornal } & \text { Brasileiro de }\end{array}$ https://doi.org/10.1590/2175-8239-JBN-2018-0178

Tohme, F., Mor, M. K., Pena-Polanco, J., Green, J. A., Fine, M. J., Palevsky, P. M., \& Weisbord, S. D. (2017). Predictors and outcomes of non-adherence in patients receiving maintenance hemodialysis. International Urology and Nephrology, 49, 1471-1479. https://doi.org/10.1007/s11255-017-1600-4

United States Renal Data System (USRDS). USRDS 2018 annual data report: Epidemiology of Kidney disease in 
the United States. National Institutes of Health, National Institute of Diabets and Digestive and Kidney Diseases, Bethesda, MD, 2018.

United States Renal Data System (USRDS). USRDS 2019 annual data report: Epidemiology of Kidney disease in the United States. National Institutes of Health, National Institute of Diabets and Digestive and Kidney Diseases, Bethesda, MD, 2019.

Vilay, A. M. (2019). Antibiotic Dosing in Chronic Kidney Disease and End-Stage Renal Disease: A Focus on Contemporary Challenges. Advances in Chronic Kidney Disease, 26(1), 61-71. https://doi.org/10.1053/j.ackd.2018.10.006

Virmani, S., \& Asch, W. S. (2020). The Role of the General Nephrologist in Evaluating Patients for Kidney Transplantation: Core Curriculum 2020. American Journal of Kidney Disease, article in press.. https://doi.org/10.1053/j.ajkd.2020.01.001

Xue, H., Ix, J. H., Wang, W., Brunelli, S. M., Lazarus, M., Hakim, R., \& Lacson Jr, D. (2013). Hemodialysis access usage patterns in the incident dialysis year and associated catheter-related complications. American Journal of Kidney Diseases, 61, 123-130. https://doi.org/10.1053/j.ajkd.2012.09.006

Wick, J. P., Turin, T. C., Faris, P. D., Macrae, J. M., Weaver, R. G., Tonelli, M., ... \& Hemmelgarn, B. R. A. (2017). Clinical Risk Prediction Tool for 6-Month Mortality After Dialysis Initiation Among Older Adults. American Journal of Kidney Diseases, 69(5), 568-575. https://doi.org/10.1053/j.ajkd.2016.08.035

Yalamarti, T., \& Janice Lee, J. (2019). Fentanyl accumulation in renal disease causing serotonin syndrome. Chest Journal, 156(4), 1961-1963. https://doi.org/10.1016/j.chest.2019.08.1945

Zunta, R. S. B., \& Lima, A. F. C. (2018). Análise de glosas técnicas em centro cirúrgico de hospital geral privado. Revista Rene, 19, e3401. https://doi.org/10.15253/2175-6783.2018193401

\section{Copyrights}

Copyright for this article is retained by the author(s), with first publication rights granted to the journal.

This is an open-access article distributed under the terms and conditions of the Creative Commons Attribution license (http://creativecommons.org/licenses/by/4.0/). 